\title{
INFLUENCE OF PARENTAL OCCUPATIONAL STRESS ON EMOTIONAL MATURITY OF ADOLESCENTS
}

\author{
K. YASHODA ${ }^{1} \&$ T. KALYANI DEVI ${ }^{2}$ \\ ${ }^{I}$ Research Associate, Child Development, All India Coordinated Research Project o Home Science, Professor \\ Jaya Shankar Telangana State Agricultural University, Rajendranagar, Hyderabad, India \\ ${ }^{2}$ Professor, Human Development and Family Studies, Department of Home Science, \\ Sri Padmavathi Mahila Vishwavidyalayam, Tirupathi. Andhra Pradesh, India
}

\begin{abstract}
Emotions play a key role in providing a particular direction to the behavior, and thus shaping the personality according to their development. It is recognized that the emotions can completely overpower ones destruction. Only that man is wise, who is free from the grip of passion, intense emotion, lust, anger and greed. The present research study was undertaken to assess and compare the Emotional Maturity of Adolescents in relation to their Gender, grade and parental Occupational stress. The sample consisted of 480 adolescent students studying with 8th, 9th and 10th standards and their parents from Hyderabad district, 240 male students and 240 female students were included in this sample. The occupational stress index purports to measure the extent of stress which employees perceive arising from various constituent and conditions of their job. The occupational stress index was used and developed by Srivastava and Singh, and Bhargava Emotional Maturity scale was used to assess the Emotional maturity. Thus, the obtained data was analyzed using means, S.D, ' $t$ '-test. The result revealed that there was a significant difference found among the High and low Emotional maturity of adolescents, by occupational stress of fathers and mothers. Significant differences were not found between the grades in high and low maturity groups with high and low occupational stress of their parents. Significant differences were found between the genders in high and low maturity groups with high and low occupational stress of their parents.

KEYWORDS: Parental Occupational Stress, Grade, Gender, Emotional Maturity \& Adolescence
\end{abstract}

Received: Jun 19, 2017; Accepted: Jul 08, 2017; Published: Jul 19, 2017; Paper Id: IJESRAUG20175

\section{INTRODUCTION}

Occupational stress refers to a situation, where, occupation related factors interact with employee to change, disrupts or enhance his psychological and physiological conditions such that, the person is forced to deviate from normal functioning (Maninderjit, 2012).

According to Indian employees, the top three reasons for stress at workplace include unclear or conflicting job expectations, inadequate staffing (lack of support, uneven workload in group) and lack of work/life balance.

Occupational stress can be defined as the harmful physical and emotional response that occurs, when the requirements of the job do not match the capabilities, resources the negative impact of stress can have far reaching effects on areas outside of the care giving role for parents of high stress, including marital satisfaction, family adaptability, functioning of siblings, and social isolation. Parents reporting negative family functioning may also 
encounter fewer positive interactions with their child.

Parental stress has direct negative effects on parental well-being; the effects of such strain extend to their children. High parental stress levels have been associated with increased child behavioral problems and less-than-optimal outcomes from treatment interventions, (Daley, Sonuga-Barke, \& Thompson, 2003; Osborne et al., 2008). The negative influence on child outcome further highlights the importance of understanding the most salient contributing variables to the unique stress profile in parents of high stress.

Antoinette and Kyong (2011) conducted a study on the effects of parenting stress, perceived mastery and maternal depression on parent-child interaction. A secondary data analysis using data for 2,650 mothers from the fragile family and child well being was conducted. The results suggested that the parenting stress undermines the sense of perceived mastery which, in turn, results in depression. Moreover, the results also indicate the parenting stress directly affects maternal depression and parent - child interaction. There was no support for the hypothesis that parenting stress undermines the senses of perceived mastery which, in turn, results in depression, which affects parent- child interaction

Bolino and Turnley (2005) explored the relationship between a specific type of organizational citizenship behavior namely, individual initiative and role overload, job stress and work family conflict. Results from a sample of 98 couples indicated that higher level of individual initiative (as assessed by the spouse or significant other) are associated with higher levels of employee role overload, job stress, and work family conflict. The findings also suggested that the relationship between individuals initiative and work family conflict was moderated by gender, such that the relationship was stronger among women than among men.

\section{OBJECTIVES OF THE STUDY}

- To find out the influence of parental occupational stress on emotional maturity of adolescents.

- To know the grade differences in emotional maturity of adolescents by parental occupational stress.

- To examine the gender differences in emotional maturity of adolescents by parental occupational stress.

\section{HYPOTHESES}

The following hypotheses were tested in the present study:

- There is significant difference found between high and low emotional maturity of adolescents by occupational stress of fathers and mothers

- There is no significant difference found between the grades in high and low emotional maturity groups, with high and low occupational stress of their parents.

- There is no significant gender difference found in both high and low emotional maturity groups of parents with low occupational stress.

\section{METHODOLOGY}

\section{Research Method}

Descriptive survey method was used. 


\section{Sample}

Sample of 480 adolescents They were selected randomly from 8th, 9th, 10th grades of Private schools in Hyderabad city. The sample included 240 boys and 240 girls and their parents.

\section{Tools Used}

To measure emotional maturity of the respondents, the scale developed by Singh and Bhargava (2011) was used. This scale measures the different aspects of emotional maturity. The dimensions of the scale are Emotional instability, Emotional regression, Social maladjustment, Personality disintegration, and Lack of independence. Emotional maturity scale has a total of 48 items and distributed over 5 dimensions. Emotional instability has 10 items, emotional regression 10 items, social maladjustment 10 items, personality disintegration has 10 items and lack of independence has 8 items. The occupational stress index purports to measure the extent of stress which employees perceive arising from various constituent and conditions of their job. Occupational stress index developed by Srivastava and Singh.

The scale consists of 46 items, each to be rated on the five-point scale. Out of 46 items, 28 are 'true-keyed' and rest 18 are false-keyed. The items relate to almost all relevant components of the job life, which cause stress in some way or the other, such as, Role over-load, Role ambiguity, Role conflict, Group and Political Pressures, Responsibility for Persons, Under Participation, Powerlessness, Poor Peer Relations, Intrinsic Impoverishment, Low Status, Strenuous Working Conditions and Unprofitability.

Statistical analysis: Percentages, Means, S.D, ' $t$ '-test and analysis of variance (ANOVA) was used for data analysis.

\section{RESULTS AND DISCUSSIONS}

The results of the study are presented below.

Table 1: Mean, SD and 'T Values of High \& Low Emotional Maturity of Adolescents by Occupational Stress

\begin{tabular}{|c|c|c|c|c|c|c|c|}
\hline \multirow{3}{*}{ S. No. } & \multirow{3}{*}{$\begin{array}{c}\text { Occupational } \\
\text { Stress }\end{array}$} & \multicolumn{6}{|c|}{ Emotional Maturity } \\
\hline & & \multicolumn{3}{|c|}{ High } & \multicolumn{3}{|c|}{ Low } \\
\hline & & Mean & SD & 'T' Value & Mean & SD & 'T' Value \\
\hline $\begin{array}{l}1 . \\
2 .\end{array}$ & $\begin{array}{l}\text { High } \\
\text { Low }\end{array}$ & $\begin{array}{l}207.40 \\
179.20\end{array}$ & $\begin{array}{l}11.67 \\
10.59\end{array}$ & $19.47 * *$ & $\begin{array}{l}207.80 \\
180.40\end{array}$ & $\begin{array}{c}10.20 \\
9.45\end{array}$ & $21.75^{* *}$ \\
\hline
\end{tabular}

** Significant at 0.01 level

For parents with high and low occupational stress in high maturity group, the mean values were 207.40 and 179.20 and SD's 11.67 and 10.59, and 't' value was significant. In low maturity, the mean values were 207.80 and 18.40 and SD's were 10.20 and 9.45. Hence, it is concluded that in this group also significant difference was found in emotional maturity of adolescents, parents with high and low occupational stress. Hence the hypothesis was rejected. Here, it was noticed that parents with low occupational stress had high emotional maturity than the high stress parents. This may be, because of low stress parents spend more time with their adolescents and showing much care, concern, love and affection. These aspects help them to become emotionally matured persons. 
High and Low Emotional Maturity of Adolescents by Occupational Stress

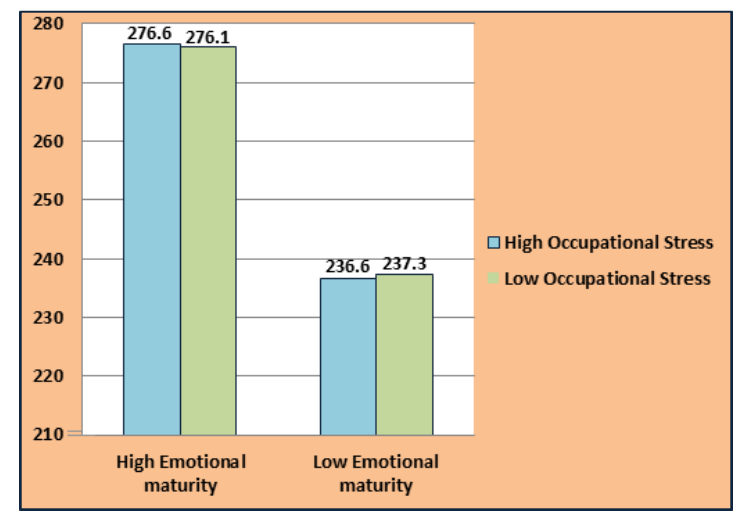

Figure 1

Table 2: High and Low Emotional Maturity of Adolescents by Occupational Stress of Fathers and Mothers

\begin{tabular}{|c|c|c|c|c|c|c|c|c|}
\hline \multirow{3}{*}{ S. No. } & \multirow{3}{*}{\multicolumn{2}{|c|}{ Occupational Stress }} & \multicolumn{6}{|c|}{ Emotional Maturity } \\
\hline & & & \multicolumn{3}{|c|}{ High } & \multicolumn{3}{|c|}{ Low } \\
\hline & & & Mean & SD & 'T' value & Mean & SD & 'T' value \\
\hline $\begin{array}{l}1 . \\
2 .\end{array}$ & $\begin{array}{l}\text { Fathers } \\
\text { Mothers }\end{array}$ & $\begin{array}{l}\text { High } \\
\text { Low } \\
\text { High } \\
\text { Low }\end{array}$ & $\begin{array}{l}207.80 \\
178.60 \\
207.90 \\
179.30\end{array}$ & $\begin{array}{l}11.47 \\
10.91 \\
11.28 \\
10.94\end{array}$ & $\begin{array}{l}19.94 * * \\
19.77 * *\end{array}$ & $\begin{array}{l}207.50 \\
180.90 \\
207.30 \\
180.30\end{array}$ & $\begin{array}{l}10.50 \\
8.96 \\
10.65 \\
9.14\end{array}$ & $\begin{array}{l}21.32 * * \\
21.31 * *\end{array}$ \\
\hline
\end{tabular}

** Significant at 0.01 level

Mean, SD and ' $\mathrm{t}$ ' values of High and low emotional maturity scores of adolescents by their occupational stress of fathers and mothers are given in table 3.The results shows that fathers with high and low occupational stress, in high emotional maturity group, the mean values were 207.80 and 178.60 and the corresponding SD values were 11.47 and 10.91, respectively. The 't' values were significant. There was a significant difference in the emotional maturity between the high and low occupational stresses of fathers at 0.01 levels. With regard to the fathers with high and low occupational stress in low emotional maturity, the mean values were 207.50 and 180.90 and SD's were 10.50 and 8.96 . It was found from the results that, in this group also significant differences were found at 0.01 levels. With regard to mother's occupational stress, in high maturity group, the mean values for high and low emotional maturity were 207.90 and 179.30 and in the low maturity group, the mean values were found to be 207.30 and 180.30 , respectively. Significant differences were found between the high and low occupational stresses of mothers in both the high and low emotional maturity group.

Hence, it clearly says that occupational stress of fathers and mothers have influence on maturity of adolescents. Fathers and mothers with low stress have high emotional maturity than to high stress fathers.

Table 3: Mean, SD and 'T' Values of High \& Low Emotional Maturity of Different Grades by Occupational Stress

\begin{tabular}{|c|c|c|c|c|c|c|c|c|}
\hline \multirow{2}{*}{ S. No. } & Occupational & \multicolumn{4}{|c|}{ High Emotional Maturity } & \multicolumn{3}{|c|}{ Low Emotional Maturity } \\
\cline { 3 - 9 } & Stress & Grades & Mean & SD & 'F' value & Mean & SD & 'F' value \\
\hline & & $8^{\text {th }}$ & 204.97 & 11.20 & & 177.19 & 14.03 & \\
& & $9^{\text {th }}$ & 208.43 & 12.68 & & 180.68 & 7.86 & \\
1. & High & $10^{\text {th }}$ & 208.36 & 10.99 & $1.07^{\mathrm{NS}}$ & 180.43 & 6.60 & $1.41^{\mathrm{NS}}$ \\
2. & Low & $8^{\text {th }}$ & 206.79 & 9.00 & $1.76^{\mathrm{NS}}$ & 178.61 & 11.24 & $1.26^{\mathrm{NS}}$ \\
& & $9^{\text {th }}$ & 206.39 & 9.76 & & 181.00 & 8.44 & \\
& & $10^{\text {th }}$ & 210.34 & 11.41 & & 181.70 & 8.24 & \\
\hline
\end{tabular}


NS: Not significant

It is concluded from the above results that high and low occupational stress were not influenced in high and low maturity groups between the grades.

Table 4: Mean, SD and ' $T$ ' Values of High and Low Emotional Maturity of Boys and Girls by Occupational Stress

\begin{tabular}{|c|c|c|c|c|c|c|c|c|}
\hline \multirow{2}{*}{ S. No } & \multirow{2}{*}{$\begin{array}{c}\text { Cccupational } \\
\text { Stress }\end{array}$} & \multicolumn{3}{|c|}{ High Emotional Maturity } & \multicolumn{3}{c|}{ Low Emotional Maturity } \\
\cline { 3 - 9 } & & Gender & Mean & SD & 'T' Value & Mean & SD & 'T' Value \\
\hline & & Boys & 200.04 & 6.13 & & 176.80 & 10.77 & \\
1. & High & Girls & 209.70 & 12.15 & $5.47^{* *}$ & 186.80 & 5.00 & $6.67^{* *}$ \\
2. & Low & Boys & 204.10 & 6.22 & $3.02^{* *}$ & 179.20 & 9.87 & $4.96^{* *}$ \\
& & Girls & 209.10 & 10.99 & & 185.80 & 4.46 & \\
\hline
\end{tabular}

** Significant at 0.01 level

Mean, SD and 't' values of emotional maturity of boys and girls by occupational stress are given in table 4 . The results indicated that for parents with high occupational stress in high maturity group, the mean values were 200.40 and 209.70 and the corresponding SD values were 6.13 and 12.15 , respectively. The ' $t$ ' values were found to be significant at 0.01 level. It means that, for parents with high occupational stress, girls were found to be low in their emotional maturity. The mean values of boys and girls were 204.10 and 209.10 with SD's of 6.22 and 10.99. Significant difference was found in this group. Boys seem to be high in their maturity than girls, because of their greater exposure and encouragement.

In the case of low emotional maturity, the mean values for boys and girls were 176.80 and 186.80 and the corresponding SD values were 6.67 and 4.96, respectively. The ' $t$ ' values were found to be significant at 0.01 level. In the case of parents with low occupational stress, the mean values of boys and girls were 179.20 and 185.80 with SD's 9.87 and 4.46, respectively. There was a significant difference between boys and girls.

\section{CONCLUSIONS}

From the above study, it is concluded that parents with low occupational stress had high emotional maturity than the high stress parents.

Significant differences are found between the high and low occupational stresses of mothers in both the high and low emotional maturity group.

High and low occupational stresses are not influenced in high and low maturity groups between the grades.

Significant difference is found in this group. Boys seem to be high in their maturity than girls, because of their greater exposure and encouragement.

Tips for Managing Stress: Stress is a universal syndrome, comprised of various characteristics and symptoms affecting different human beings differently. Stress is a normal physical response to events that make you feel threatened or upset your balance in some way. Following are few tips to manage stress:

- Learn to be assertive and express your feelings and needs in interpersonal relationships.

- Consider taking an assertiveness training course, if necessary.

- Don't over commit yourself. Learn to say no. 
- Stop unproductive worrying and focus on constructive problem solving. For example, when you start worrying that you'll never finish your presentation in time, instead think: "If I stay focused and move forward one step at a time, I'll make progress."

- Strive to be a good person, not a perfect person. Tell yourself that you do not have to be everything to everyone all the time.

- $\quad$ Eat well-balanced meals: Avoid excessive amounts of sugar, caffeine, fat, salt and food additives.

- Eliminate cigarettes, alcohol and drugs from your lifestyle.

- Get plenty of rest to increase your ability to resist stress.

- Exercise regularly (under the advice of your physician) to help you release tension and withstand the impact of stress.

- Have fun and laugh! Humor can significantly reduce stress. Enjoy the company of others and remember to laugh at yourself.

- Consider participating in a stress management seminar. Ask your employer if they offer any within your organization.

\section{REFERENCES}

1. Antoinette, Y.F and Kyong, L.S. (2011). The effects of parenting stress, perceived mastery and maternal depression on parentchild interaction. Journal of Social Service Research. 37(5): 516-525.

2. Bolino, M.C and Turnley, W.H. (2005). The personal costs of citizenship behavior: The relationship between individual initiative and role overload, job stress and work family conflict. Journal of Applied Psychology. 90(4): 740-748.

3. Daley, D., Sonuga-Barke, E. S., \& Thompson, M. M. (2003). Assessing expressed emotion in mothers of preschool AD/HD children: Psychometric properties of a modified speech sample. British Journal of Clinical Psychology.42(1): 53-67.

4. Maninderjit, S.P. (2012). Occupational stress amongst teachers of professional colleges in Punjab. Management. ParipexIndian Journal of Research. 1(9): 112-118.

5. Singh Y and Bhargava M. (2011). Manual for revised Emotional Maturity Scale. Agra: National Psychological Corporation

6. Srivastava, A.K and Singh, A.P (2004). Manual of Occupational stress Index. Manovaignanic Parikshan Sansthan, Sanjay Nagar Colony, Varanasi. 